\title{
Supporting Children with Learning Disabilities
}

\author{
John K. McNamara \\ Brock University
}

\begin{abstract}
This paper presents a prevention model for supporting children with learning disabilities. The model holds that children can be identified as at-risk for learning disabilities by identifying and supporting potential academic failure early in their elementary years. A prevention model includes two elements, identification and instruction. Identification entails recognizing those children at-risk for poor achievement in the early primary grades. The second component of the model is to implement a program of effective instruction that focuses on the explicit teaching of phonological processing skills and eventually, teaching these skills in context. Early effective instruction will create an environment that enables children with learning disabilities to experience success. Early success for children who may be at-risk for many years of struggle and frustration cannot be underestimated. Enabling success at an early age creates a positive cycle where efficacy and motivation is fostered in turn alleviating the academic and psychosocial stresses and challenges often associated with learning disabilities.
\end{abstract}

Early intervention is a term often used when working with children at-risk for learning disabilities. However, it is difficult to know what is meant by this term. When working with educators, administrators, parents, and children common questions include, "What program will work most effectively to increase children's reading levels?" and "Will this program increase children's reading level to one commensurate with their grade?" Answering these questions is difficult as it depends on a number of factors. However, research is clear that early identification and intervention can have a profoundly positive effect on social-emotional and achievement outcomes for children with learning disabilities (Perry, McNamara, \& Mercer, 2001). Individuals whose problems are addressed early are more self-assured and better able to cope with their specific disabilities throughout their lives (e.g., they are better self-advocates, more likely to pursue tertiary education, and more likely to be successfully employed

John McNamara is a faculty member in the Department of Child and Youth Studies at Brock University. He is an educational psychologist interested in studying the developmental health of children and youth with learning disabilities. 
after school). In contrast, students whose difficulties are not adequately addressed in school are at risk for developing social-emotional and achievement related difficulties later in life (e.g., problems in relationships, stress and depression, difficulty attaining and maintaining employment). Therefore, a model of early effective intervention is imperative for educators and parents to consider.

This paper explores three issues related to developing a model of early intervention aimed at supporting children with learning disabilities. First, all stakeholders concerned with education for children with learning disabilities must develop a common understanding about the term "learning disabilities." It is easy to agree with this idea but more often than not there is little consensus about what is meant by learning disabilities (Finn, Rotherham, \& Hokanson, 2001). Such confusion often leads to uncertainty in classrooms and disagreement among researchers and policymakers. This paper presents an understanding of learning disabilities developed and substantiated by current research from the field. Second, there are many new teachers entering the field without an adequate understanding of how students with learning disabilities learn. If education hopes to focus on strengthening academic results for all students it is imperative that educators have the skills to work with individual differences and to address the specific needs of children with learning disabilities. The current paper discusses the issue of teacher education and presents ideas about supporting future educators who will work with students with LD. Third and perhaps most importantly, this paper describes a model of prevention for children with LD. A common term in learning disabilities education is the Matthew Effect, or the rich get richer and the poor get poorer (Stanovich, 1986). There is substantial evidence that poor readers in the early grades remain poor readers throughout later grades (Shaywitz, et al., 1999). In fact, it is extremely difficult to remediate poor reading. The implication for special education is that we must prevent students at-risk for learning disabilities from becoming poor readers. Therefore, the final section of this paper considers a prevention model whereby young children at-risk for reading failure are supported before they are formally diagnosed with a learning disability.

\section{A Common Understanding of Learning Disabilities}

As mentioned, there is often little consensus about what is meant by the term learning disabilities. The continuum of understanding ranges from the idea that learning disabilities are ontologically-based dysfunctions to the idea that the notion of learning disabilities is simply a social construct. This range of 
understanding becomes problematic when designing effective programs for the students in question. Working towards a common understanding will in turn, facilitate effective programs throughout and across provinces and territories. Currently, the country is well positioned to develop a common understanding given the recent focus on educational accountability as well as the recent publication of a new definition of learning disabilities from the Learning Disabilities Association of Canada (LDAC) (2001). However, it is important to understand that developing such a common understanding calls for politicsfree, science-based inquiry into the phenomenon. Such inquiry is aligned with the recent emphasis on developing understanding about school programs that is based on scientific research (Murray, 2002). This approach is particularly relevant to the field of learning disabilities. Research in this field suggests that learning disabilities are synonymous with the concept of unexpected underachievement (Lyon, et al., 2001). In other words, children with learning disabilities are achieving in specific areas below levels that might otherwise be expected. A key idea here is that underachievement is attributed to processing problems associated with minor neurobiological dysfunction.

In general, there are four basic elements that are common to learning disabilities (Lyon, et al., 2001). These four elements underlie most definitions of learning disabilities including that proposed by the LDAC (2001). The first element is heterogeneity. Learning disabilities is a broad term that describes many different forms. A common understanding emerging in the field of LD is that there are seven domains under the general concept of learning disabilities. The seven domains include listening, speaking, basic reading, reading comprehension, arithmetic calculation, mathematic reasoning, and written expression. Each of these domains entails a different type of processing dysfunction. For example, basic reading disabilities are associated with poor decoding and work recognition, a skill associated with phonological processing. In other words, many children with a basic reading disability have phonological processing problems that affect their ability to decode words efficiently (Stanovich, 1986). On the other hand, a reading comprehension disability may not be associated as much with phonological processing but rather with working memory processing. A decreased working memory capacity may affect an individual's ability to retrieve information efficiently, a skill necessary for comprehension. It is important to understand that children may have a learning disability associated with one, two, or many of these domains. This type of diversity within the population of individuals with learning disabilities makes it difficult to establish effective programs. Therefore, the challenge that awaits the field is to develop separate evidence-based definitions for each of these domains. This process will enable educators and researchers to establish 
programs associated with each domain. When a child experiences acrossdomain difficulties, the associated programs may be combined.

The second element of learning disabilities is the notion that children with learning disabilities have intrinsic processing problems that are associated with minor neurological dysfunction. This idea has been a staple of the concept of learning disabilities since its inception in 1963. There is considerable evidence that the processing problems associated with learning disabilities have a neurological basis. Specifically, children with learning disabilities show minor disruptions in neurological functioning in different parts of the central nervous system. For example, research on basic reading disabilities points to anomalous structure and function in the language regions of the brain (Leonard, 2001). Specifically, children with basic reading disabilities exhibit minor dysfunction in the superior temporal lobe and the posterior parietal regions of the central nervous system. Recent research on memory processing and learning disabilities reveal that this type of difficulty may be connected with a dysfunction in the pre-frontal dorsal lateral region of the brain. Critics of neurobiological research suggest that there are many factors and confounds that could lead to discrepant findings in neurological function between children with and without learning disabilities (Poplin, 1988). Such confounds include task selection and design problems, or the role that environment plays on neurological functioning. However, research has attempted to control for such confounds by, for example, exploring the neurological structure and function of twins with learning disabilities (Pennington, 1995). The results of such research invite the notion that when environment and methodological factors are controlled, neurological differences remain. In general, a converging body of research indicates a pattern of neurological organization in children with LD that is different from children without LD.

However, even assuming that children with LD do have minor neurological disruptions that affect how they process information, it is important to recognize the impact that effective early instruction can have on their capacity to learn. There is an emerging body of research that illustrates the impact of environment on learning, learning potential, and even neurological functioning. For example, Keating and Hertzman (1999) describe the importance of early environmental influence on human development. Findings from their work suggest that early positive experiences may even contribute to changes in neurological structure and physiological function, constructs often thought to be stable genotypic traits. In general, we should recognize that children may have a neurological susceptibility towards learning disabilities, but recognize also that high quality instruction remains the most predictive variable of academic success. 
The third element of learning disabilities is the discrepancy between aptitude and achievement that is consistent with almost every definition of learning disabilities. In general, the discrepancy idea entails that a child's academic underachievement in a particular area is not consistent with their inherent ability or potential. This discrepancy is measured typically by comparing IQ scores with achievement scores. Since the inception of the learning disability construct, the discrepancy model has been a common method of diagnosing learning disabilities. However, this model is becoming increasingly problematic. The purpose of this paper is not to review the current problems associated with the discrepancy model, but it is important to mention briefly the current problems with this identification model. One difficulty raised most prominently by Thorndike (1963) is that IQ scores reflect only a gross estimate of current general cognitive functioning rather than a measure of learning potential. The idea that IQ scores represent a measure of learning potential is fraught with psychometric and theoretical difficulties. The second problem with using IQ scores to identify children with learning disabilities is that when diagnoses are made based on the existence of an IQ-achievement discrepancy a child may receive specialized instruction. If the instruction is effective, the student's level of achievement will increase. In fact, it may increase to a point where a significant discrepancy no longer exists and the student may lose eligibility for resources. Does this mean that because a significant IQ-achievement discrepancy has disappeared that the learning disability has been remediated? Certainly not. It appears that effective instruction has remediated the learning disability, but in fact it has simply eliminated the presence of the current diagnostic criteria for learning disabilities. More often than not, students without resources soon redevelop the required psychometric criteria.

The final and most pertinent problem with the discrepancy model is that it constitutes a wait-to-fail model (Shaywitz, et al., 1999). This means that in order to meet the discrepancy criteria a student has to exhibit academic performance in a specific area that is significantly below their grade level. The criteria usually equate to achievement that is two years below grade level. This is problematic because it means necessarily that children cannot be classified formally as learning disabled until grade 3 or 4 , when a 2-year discrepancy between academic performance and grade level can emerge. By this time a student is lagging two or three years behind his/her peers, far too late to implement effective instruction.

In general, the notion of a discrepancy between ability and achievement is valid, however, it is the diagnostic tools associated with measuring this discrepancy that are problematic. One way to address this problem is to jettison the use of IQ tests and develop a three-tier model of 
assessment for children with learning disabilities. The first tier of this model is an assessment of the processing skills associated with the area of academic difficulty. Processing problems are the most direct manifestation of the assumed neurological dysfunction associated with learning disabilities. There are many well-established norm-referenced processing-based assessments aimed at measuring the processing difficulties consistent with learning disabilities. The second tier of this assessment model focuses on the notion of resistance to treatment. Approximately 3-4\% of poor readers do not respond appropriately to even the most effective instruction. The notion of treatment resistors then becomes an important tool in identifying children with LD (Torgesen, 2000). When this idea is applied to assessment of learning disabilities, the role of the general and special educator is to monitor those students who consistently fail to respond to instruction. These children are then identified as being at-risk for learning disabilities. The third tier of this model centers on the notion of "unexpected underachievement." A primary characteristic associated with learning disabilities is that students with learning disabilities achieve at unexpectedly poor levels compared to their potential. Instead of waiting for an IQ-achievement discrepancy to manifest, unexpected underachievement can be documented by direct comparisons of students' age and grade with their academic functioning in specific academic areas (Lyon et al., 2001). General and special educators become important conduits of information about such comparisons. Further, documenting such unexpected underachievement can occur within early primary grades, well before a formal discrepancy can be established.

Assuming the validity of this 3-tier model, a student would be identified as having a learning disability if they were achieving in a specific academic domain at a level below their expected grade and age, they measured below grade level in certain processing skills, and they were not responding effectively to quality instruction. A child who fit this description would be consistent with our current definition of learning disabilities. Furthermore, by adopting this type of identification model, educators will be able to identify children at-risk for learning disabilities at an early age since all three of these assessment tiers can be done in kindergarten or even before.

\section{Teacher Education}

Current prevalence rates for learning disabilities within the general population of children range from 5-10\% (Torgesen, 1998). As such, teachers should expect to have at least one or two students with learning disabilities in their classrooms. Over the course of a teacher's career this means that they may encounter 25-50 
children with learning disabilities. However, there is a substantial robust body of research that explored the preparation of teachers to work with students with special needs and found much evidence showing that teachers are unprepared to teach students with special needs (Vaughn \& Klingner, 1998). This finding is particularly relevant to Canadian education given the trend toward full inclusion in our schools (Friend, Bursack, \& Hutchinson, 1998).

Seventy to $80 \%$ percent of the difficulties experienced by students with learning disabilities are associated with reading (Torgesen, 1998). In fact, reading and literacy are perhaps the most prevalent issues for all students with special needs. As mentioned earlier, once children fall behind in their reading achievement they rarely catch up. Therefore, it is imperative that new teachers entering the field of education have a solid foundation in reading and how to assess informally whether children in their class are reading significantly below grade-level norms. However, many teachertraining institutions do not require prospective teachers to take a course on the reading process.

A second issue related to teacher training is that educators do not have sufficient knowledge of the evidence-based practices that are associated significantly with preventing academic failure (Lyon, et al., 2001). Often there is a total disconnect between educational research and application to the classroom. This is particularly true within the discipline of educational psychology and special education. Recognition of this fact has led education policy makers to call for a tighter link between research and practice and, more than ever, the field of education, and particularly special education, is moving towards a model of programming that is based on evidence-based practices. An example of this shift is the recent US fiscal policy that saw the largest spending increase directed towards a call for educators to build school programming based on scientific research (Murray, 2002). The result has been schools of education preparing teachers to base their work on scientific evidence. Specifically, teachers-to-be are learning to translate evidence-based psychological principles into practice. The result of this shift in training models should be educators who are aware of the most recent research-based findings on how children learn to read, and further, what can be done to prevent children from falling behind. In general, teacher education in special education must revolve around addressing individual differences, understanding the reading process, studying and applying research, and understanding how to collaborate effectively with special educators. 


\section{Developing a Prevention Model}

Typically, children are classified as "learning disabled" when they show a discrepancy between their ability and their achievement. Diagnosing learning disabilities often relies on a model of classification that looks for a two-year discrepancy between a child's academic performance in a specific area (i.e. reading) and their grade-level expectations (measured as IQ). This is problematic because it means necessarily that children cannot be classified formally as learning disabled until grade 3 or 4 when a 2-year discrepancy between academic performance and grade level can emerge. It is not difficult to agree that this is far too late. It is therefore critical to develop methods for identifying and supporting, at an early age, students who are at-risk for learning disabilities. One such method may be thought about within a framework of prevention and as such, the following section describes a model of prevention for supporting children with LD.

A prevention model for learning disabilities holds that children can be identified as at-risk for academic failure early in their elementary years. Such models include two elements, identification and instruction. However, it is important here to make a distinction between identification and classification. Typically, classification entails a formal diagnosis made by a qualified professional. Classification also typically entails an Individual Education Plan (IEP) and specific funding tied to the individual. As mentioned in a previous section, this model of classification is problematic in that it is a wait-to-fail model and is not initiated until a child is in grade three or four. Within a prevention model identification entails identifying a child as being at-risk for academic failure. This does not mean identifying a child as having a particular disability or special need. The basic underlying assumption of the model is that we prevent the failure normally associated with a learning disability.

The idea of identification within a prevention model calls for the development and integration of tools for identifying early predictors of reading failure. The National Research Council on Preventing Reading Difficulties in Young Children (Snow, Burns, \& Griffin, 1999) reported that children in kindergarten can reliably be identified as "at-risk" for word reading difficulty on the basis of their performance on tasks that assess phonemic awareness and naming abilities. The specific measures that are most predictive of later reading ability are letter sound correspondence, blending sounds into words, and the ability to name letters rapidly (Torgesen, Wagner, Rashotte, Burgess, \& Hecht, 1997). Given the results of research on the predictive nature of early measures of phoneme awareness, many early identification tools have been published. For example, Torgesen and Bryant (1994) have published the Test of 
Phonological Awareness (TOPA) and the Comprehensive Test of Phonological Processing (CTOPP) both aimed at using measure of phonological awareness to identify children and youth with deficient skills in these areas. Torgesen proposes that phonological processing consists of three sub skills, phonological awareness, phonological memory, and rapid naming. Tests such as the TOPA and CTOPP are useful in that they may be administered to children as early as age 5 and also may be administered by special education teachers. There are many published assessment tools that measure phonological processing and may be useful for schools and particularly educators of early grades (see Torgesen \& Mathes, 2000 for review).

The idea of effective instruction with a prevention model calls for early effective practices to be developed and integrated in the early elementary years. This type of instruction will be useful for those children at-risk for reading failure but also to those children who are consolidating their reading skills. The National Research Council on Preventing Reading Difficulties in Young Children (Snow, et al., 1999) also examined early reading instruction and found that the explicit teaching of phoneme awareness and phonological processing was especially effective in kindergarten and Grade one. The NRC found that early effective intervention may substantially reduce the number of children who would eventually be diagnosed with learning disabilities. Torgesen (2000) found that when an effective intervention is used with the bottom $18 \%$ of the student population and assuming that it works with $70 \%$ of them, the number of at-risk children requiring services is reduced from $18 \%$ to $5 \%$. This finding is impressive, and begs the question, what is effective instruction? Research remains somewhat unclear about this, but some important findings have emerged. Effective instructional programs in phonological processing begin with oral language activities. Such a task may involve children being explicitly taught how to pronounce the sounds associated with letters. From here, instruction may involve educators explicitly modelling for children how sounds can be blended together. Instructional programs should also include opportunities for children to apply their ability to manipulate phonemes to actual reading or spelling activities. In general, effective programs in phonological processing should help children to become aware of individual phonemes in words (Hoien, Lundberg, Stanovich, \& Bjaalid, 1995). (For a review of some current published programs in phonological awareness see Torgesen \& Mathes, 2000).

An important aspect of adopting a prevention model is the changing role of the special educator. In the past, special educators were seen often as a tertiary person within a school who was concerned mainly with assessing and working with students who were already behind in their reading skills. Their 
role within a prevention model is working with classroom teachers in ensuring that students at-risk for academic difficulties do not fall behind. This calls for collaboration between general and special educators starting in kindergarten. Therefore, the role of the special educator is no longer simply assessment and identification. Rather, the special educator is explicitly involved in program implementation, monitoring and evaluation. Specifically, the special educator should be thought of as the school-based expert in effective programming for students at-risk for academic failure, but also in programs aimed to ensure that all students are succeeding academically. Special educators should also understand thoroughly how to implement programs, monitor their implementation, and evaluate whether the programs are working effectively.

A prevention model has many advantages all of which are based on scientifically sound evidence that once children are reading behind their peers they rarely catch up (Torgesen, 2000). The foremost advantage of a prevention model is that early identification and intervention may substantially reduce the number of children that in later grades may require significant remedial assistance. This has fiscal as well as social implications. In general, a prevention approach enables funding to be targeted at intervention rather than expensive eligibility determination practices. This means that funds are allocated to a construct that is closely tied to accountability rather than the notion of access. In essence, this is a shift away from a civil rights orientation towards strengthening academic results.

\section{Conclusion}

Since the definition of learning disabilities was first forged in 1963, stakeholders concerned with children with learning disabilities have accomplished a great deal. Educators, administrators, and researchers have progressed towards an understanding about the underlying difficulties experienced by children with learning disabilities and also are beginning to understand how to most effectively meet the educational and emotional needs of these children. However, this progression is not complete. As outlined in this paper, there remains a substantial amount of confusion and disagreement among the stakeholders concerned with learning disabilities. Given these challenges, this paper has aimed to acknowledge how education may address this situation. First, it is important that stakeholders concerned with supporting children with LD work towards a common understanding about what is meant by the term learning disabilities. Furthermore, this common understanding must permeate throughout Canada's teacher education programs. By establishing such a common understanding of learning disabilities stakeholders can collectively 
work towards implementing a prevention model of learning disabilities. Such a model emphasizes preventing the academic underachievement often associated with learning disabilities. There are two primary components of a prevention model: identification and instruction. Identification entails recognizing those children at-risk for poor achievement in the early primary grades. The second component of the model is the implemention of a program of effective instruction that focuses on the explicit teaching of phonological processing skills and eventually, teaching these skills in context. The advantages of adopting a prevention model are many. First, early effective instruction will create an environment that enables children with learning disabilities to experience success. Early success for children who may be at-risk for many years of struggle and frustration cannot be underestimated. Enabling success at an early age creates a positive cycle where efficacy and motivation is fostered in turn alleviating the Matthew effects often associated with children with learning disabilities (Stanovich, 1986). A prevention model also has fiscal advantages. By serving children at-risk for reading failure at an early age, fewer children will require expensive special education services in the later grades. A secondary advantage associated with this is that education systems will be less susceptible to legal disputes over whether children are receiving appropriate educational services. Of course, it is unrealistic to assume that adopting a prevention model will be eliminating all reading difficulties and thus all legal disputes. As Torgesen (2000) points out, there may be a small population of children who resist even the most effective instruction. However, prevalence estimates of children who fall into this category are $2-4 \%$. Therefore, we could realistically expect that with early, effective instruction and environments we can strengthen academic results of the majority of children at-risk of learning disabilities.

\section{Author's Note}

This work was supported by research grant \#410-2002-0593 from the Social Sciences and Humanities Research Council of Canada.

\section{References}

Finn, C. E., Rotherham, A. J., \& Hokanson, C. R. (2001). Conclusions and principals for reform. In C. E. Finn, A. J. Rotherham, \& C. R. Hokanson (Eds.). Rethinking special education for a new century. Fordham Foundation Publications. 
Friend, M., Bursack, W., \& Hutchinson, N. (1998). Including exceptional children. Toronto, ON: Allyn and Bacon.

Hoien, T., Lundberg, I., Stanovich, K. E., \& Bjaalid, I. (1995). Components of phonological awareness. Reading and Writing: An Interdisciplinary Journal, 7, 171-188.

Keating, D. \& Hertzman, C. (1999). Developmental health and the wealth of nations. New York: Guilford Press.

Learning Disabilities Association of Canada. (2001). A definition of learning disabilities.

Leonard, C. M. (2001). Imaging brain structure in children: Differentiating language disability and reading disability. Learning Disabilities Quarterly, 24(3), 158-176.

Lyon, G. R., Fletcher, J. M., Shaywitz, S. E., Shaywitz, B. A., Torgesen, J. K., Wood, F. B., et al. (2001). Rethinking learning disabilities. In C. E. Finn, A. J. Rotherham, \& C. R. Hokanson (Eds.). Rethinking special education for a new century. Fordham Foundation Publications.

Murray, B. (2002). Wanted: Politics-free science-based education. American Psychological Association Monitor, 33(8), 52-54.

Pennington, B. (1995). Genetics of learning disabilities. Journal of Child Neurology, 10(1), 69-77.

Perry, N., McNamara, J. K., \& Mercer, L. (2001). Policies, practices and procedures in special education. Education Exceptionalities Canada, 11, 63-89.

Poplin, M. S. (1988). The reductionist fallacy in learning disabilities: Replicating the past by reducing the present. Journal of Learning Disabilities, 21(7), 389-400.

Shaywitz, S. E., Fletcher, J. M., Holahan, J. M., Schneider, A. E., Marchione, K. E., Stuebing, K.K., et al. (1999). Persistence of dyslexia: The Connecticut longitudinal study at adolescence. Pediatrics, 104, 1351-1359.

Snow, C. E., Burns, S. M., \& Griffin, P. (1999). Preventing reading difficulties in young children. A Report to the National Research Council on Preventing Reading Difficulties in Young Children. Washington, DC: National Academy Press.

Stanovich, K. E. (1986). Matthew effects in reading: Some consequences of individual differences in the acquisition of literacy. Reading Research Quarterly, 21(4), 360-407.

Thorndike, R. L. (1963). The concepts of over and under achievement. New York: Columbia University Publications. 
Torgesen, J. K. (1998). Learning disabilities: An historical and conceptual overview. In B. Y. L. Wong (Ed.), Learning about learning disabilities. San Diego: Academic Press.

Torgesen, J. K. (2000). Individual differences in response to early interventions in reading: The lingering problem of treatment resisters. Learning Disabilities Research and Practice, 51(1), 55-64.

Torgesen, J. K., \& Bryant, B. (1994). Test of phonological awareness. Austin, TX: PRO-Ed.

Torgesen, J. K., \& Mathes, P. G. (2002). A basic guide to understanding, assessing, and teaching phonological awareness. Austin, TX: Pro-Ed.

Torgesen, J. K., Wagner, R. K., Rashotte, C. A., Burgess, S., \& Hecht, S. (1997). Contributions of phonological awareness and rapid automatic naming ability to the growth of word-reading skills in second to fifth-grade children. Scientific Studies of Reading, 1(2), 161-185

Vaughn, S. \& Klingner, J. K. (1998). Students' perceptions of inclusion and resource room settings. Journal of Special Education, 32(2), 79-88. 